\title{
Efficacy and safety of prostate artery embolization on lower urinary tract symptoms related to benign prostatic hyperplasia: a systematic review and meta-analysis
}

\author{
This article was published in the following Dove Press journal: \\ Clinical Interventions in Aging \\ II November 2016 \\ Number of times this article has been viewed
}

\section{Xiao-yan Wang \\ Huan-tao Zong \\ Yong Zhang}

Department of Urology, Beijing

Tian Tan Hospital, Capital Medical

University, Beijing, People's

Republic of China
Correspondence: Yong Zhang

Department of Urology, Beijing Tian

Tan Hospital, Capital Medical University,

No 6 Tiantan Xi Li, Dong Cheng District,

Beijing 100050, People's Republic of

China

Tel +86 I0 67098393

Fax +86 I0 6709 66II

Email I86I07II834@I63.com
Background: Prostate artery embolization (PAE) is emerging and is a promising minimally invasive therapy that improves lower urinary tract symptoms (LUTS) related to benign prostatic hyperplasia (BPH). The purpose of this article was to evaluate the efficacy and safety of PAE on LUTS related to BPH.

Materials and methods: A literature review was performed to identify all published articles of PAE for BPH. The sources included MEDLINE, EMBASE and Cochrane Library from 1980 to 2016. A systematic review and meta-analysis was conducted. The outcome measurements were combined by calculating the mean difference with $95 \%$ confidence interval. Statistical analysis was carried out using Review Manager 5.3.0.

Results: Twelve studies involving 840 participants were included. Compared with baseline, the International Index of Erectile Function (IIEF-5; International Prostate Symptom Score) scores, the quality of life scores, peak urinary flow rate $\left(Q_{\max }\right)$ and postvoid residual volume all had significant improvements during the 24-month follow-up (all $P<0.00001$ ). Both prostate volume (PV) and prostate-specific antigen had significant decrease during the 12 -month follow-up $(P<0.00001$ and $P=0.005$, respectively), except postoperative 24 months $(P=0.47$ and $P=0.32$, respectively). The IIEF-5 short form scores had significant increase at postoperative 6 months $(P=0.002)$ and 12 months $(P<0.0001)$, except postoperative 1 month $(P=0.23)$ and 24 months $(P=0.21)$. For large volume $(\mathrm{PV} \geq 80 \mathrm{~mL}) \mathrm{BPH}$, the results were similar. There were no life-threatening complications.

Conclusion: PAE is an effective, safe and well-tolerable treatment for LUTS related to BPH, including large volume (PV $\geq 80 \mathrm{~mL}$ ) BPH, with a good short-term follow-up. Studies with large number of cases and longer follow-up time are needed to validate our results.

Keywords: lower urinary tract symptoms, benign prostatic hyperplasia, meta-analysis, prostate artery embolization

\section{Introduction}

Lower urinary tract symptoms (LUTS) are main complaints resulting from benign prostatic hyperplasia (BPH), which is one of the most common diseases of aging men. ${ }^{1}$ LUTS can range in severity and have a significant impact on the quality of life (QoL).

The current treatment options include watchful waiting, medical therapy and surgical intervention. The patients refractory to preliminary treatments can be treated with surgical intervention. Transurethral resection of the prostate (TURP) is the gold standard therapy for LUTS/BPH and, for many years, has been considered the surgical treatment 
of choice and the standard of care when other treatment methods fail. ${ }^{2}$ However, TURP has significant complications, including short-term bleeding, dilutional hyponatremia, sexual dysfunction and incontinence. The complication rate is higher for patients with large volume $\mathrm{BPH}^{3}{ }^{3}$

Recently, prostate artery embolization (PAE) has started emerging and is a promising minimally invasive therapy that improves LUTS related to $\mathrm{BPH}$ and is associated with a decrease in prostate volume (PV). ${ }^{4}$ However, it is reported that as many as $25 \%$ of patients show no significant improvement in symptoms and peak flow rate. In addition, the average reduction rate in the PV after PAE was only $20 \%{ }^{5}$

The aim of this meta-analysis was to evaluate the efficacy and safety of PAE on LUTS related to BPH, which may help urologists make better choices in the case of elderly patients with large volume BPH.

\section{Materials and methods}

\section{Search strategy}

A comprehensive literature search was carried out by two independent reviewers using MEDLINE (from 1980 to 2016), EMBASE (from 1980 to 2016) and the Cochrane Central Register of Controlled Trials. The reference lists of the retrieved studies were also checked. The following search terms were used: "prostate artery embolization", "lower urinary tract symptoms" and "benign prostatic hyperplasia".

\section{Inclusion criteria}

Studies that met the following criteria were included: 1) a study design that included PAE for BPH; 2) a study that provided data on International Prostate Symptom Score (IPSS), QoL, PV, prostate-specific antigen (PSA), peak urine flow rate $\left(Q_{\max }\right)$, postvoid residual (PVR) volume and International Index of Erectile Function (IIEF-5) short form at different follow-up times, and 3) a study where its full text could be accessed. If these inclusion criteria were not met, then the study was excluded.

\section{Trial selection}

When the same study was published in various journals or in different years, the most frequently cited one was used. If the same group of researchers studied a group of subjects with multiple experiments, then each study was included. Together, we discussed each of the studies that were included and excluded.

\section{Quality assessment}

The quality of included studies was assessed using the Newcastle-Ottawa scale generating a maximum of nine stars to each study, including four stars for the selection of participants, two stars for the comparability of participants and three stars for the assessment of outcomes. Quality was assigned according to the scores so that seven to nine stars indicated high quality, four to six stars indicated middle quality and zero to three stars indicated low quality.

\section{Data extraction}

Two independent reviewers extracted the data using a predesigned form. The following information was collected from each study: 1) the name of the first author and the publication year; 2) the sample size; 3) the country in which the study was conducted; 4) data on IPSS, QoL, PV, PSA, $Q_{\max }$, PVR volume and IIEF-5 at different follow-up times and 5) the number of participants with complications. Any disputes were resolved by group consensus.

\section{Statistical analysis}

Statistical analysis was carried out using Review Manager 5.3.0. The changes in seven functional indexes were determined as differences between baseline and study completion. Outcome measurements were combined by calculating the mean difference with $95 \%$ confidence interval (CI). To quantify the effect of heterogeneity test result, $I^{2}$ heterogeneity test was used. A random-effects model was used if $I^{2}$ value was $>50 \%$; if not, a fixed-effects model was used. Publication bias was evaluated using the funnel plot.

\section{Results \\ Characteristic and quality assessment of eligible studies}

Figure 1 shows the flow diagram of the study selection process. Finally, there were nine articles involving 12 studies eligible for this meta-analysis. ${ }^{6-14}$ All of the 12 studies reported the baseline IPSSs, QoL scores, PV, PSA levels, $Q_{\max }$, PVR volume and IIEF-5 scores. All 12 studies excluded patients with malignancy, advanced atherosclerosis and tortuosity of the iliac arteries and/or prostate arteries, secondary renal insufficiency, large bladder diverticula or stones, neurogenic bladder, detrusor muscle failure, active urinary tract infection and unregulated coagulation parameters. The main characteristic and quality assessment of eligible studies are presented in Table 1.

\section{Changes after PAE IPSSs}

Six studies involving 582 participants, five studies involving 451 participants, six studies involving 479 participants and three studies involving 117 participants included 


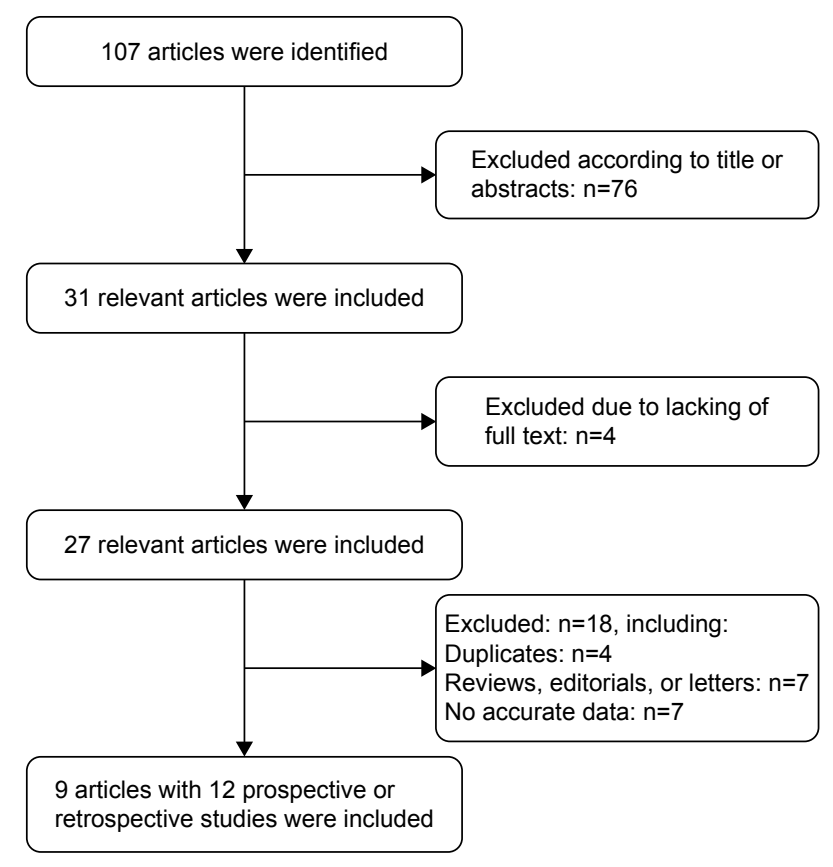

Figure I The flow diagram of the study selection process.

data representing IPSS changes at postoperative 1 month (Figure 2A), 6 months (Figure 2B), 12 months (Figure 2C) and 24 months (Figure 2D), respectively.

Compared with baseline, the IPSSs had significant decreases at postoperative 1 month (weighted mean difference (WMD) $-12.74,95 \% \mathrm{CI}-15.10$ to $-10.39, P<0.00001$ ), 6 months (WMD $-14.13,95 \% \mathrm{CI}-17.73$ to -10.54 , $P<0.00001$ ), 12 months (WMD $-16.07,95 \%$ CI -18.16 to $-13.98, P<0.00001$ ) and 24 months (WMD $-15.62,95 \%$ CI -17.41 to $-13.82, P<0.00001)$.

\section{QoL scores}

Nine studies involving 660 participants, eight studies involving 528 participants, six studies involving 414 participants and three studies involving 117 participants included data representing QoL score changes at postoperative 1 month (Figure 3A), 6 months (Figure 3B), 12 months (Figure 3C) and 24 months (Figure 3D), respectively.

Compared with baseline, the QoL scores had significant decreases at postoperative 1 month (WMD $-2.07,95 \%$ CI -2.37 to $-1.76, P<0.00001$ ), 6 months (WMD $-2.15,95 \%$ CI -2.44 to $-1.86, P<0.00001$ ), 12 months (WMD -2.81 , $95 \%$ CI -3.45 to $-2.17, P<0.00001)$ and 24 months (WMD $-2.15,95 \%$ CI -2.60 to $-1.69, P<0.00001$ ).

\section{Prostate volume}

Five studies involving 507 participants, five studies involving 386 participants, six studies involving 366 participants and three studies involving 106 participants included data representing $\mathrm{PV}$ changes at postoperative 1 month (Figure 4A), 6 months (Figure 4B), 12 months (Figure 4C) and 24 months (Figure 4D), respectively.

Compared with baseline, PV had significant decreases at postoperative 1 month (WMD $-17.33,95 \% \mathrm{CI}-21.19$ to $-13.47, P<0.00001$ ), 6 months (WMD $-31.62,95 \%$ CI -46.75 to $-16.48, P<0.0001$ ) and 12 months (WMD -30.72 , $95 \%$ CI -42.91 to $-18.53, P<0.00001)$. Although PV was also less at postoperative 24 months (WMD -16.89 , 95\% CI -62.61 to -28.83$)$, the difference was not statistically significant $(P=0.47)$.

\section{Prostate-specific antigen}

Five studies involving 520 participants, five studies involving 383 participants, six studies involving 379 participants and three studies involving 104 participants included data representing PSA changes at postoperative 1 month (Figure 5A), 6 months (Figure 5B), 12 months (Figure 5C) and 24 months (Figure 5D), respectively.

Compared with baseline, PSA had significant decreases at postoperative 1 month (WMD $-0.80,95 \% \mathrm{CI}-1.44$ to $-0.16, P=0.01$ ), 6 months (WMD $-1.15,95 \% \mathrm{CI}-1.69$ to $-0.60, P<0.0001$ ) and 12 months (WMD $-0.97,95 \%$ CI -1.65 to $-0.29, P=0.005)$. Although PSA was also less at postoperative 24 months (WMD $-0.80,95 \% \mathrm{CI}-2.37$ to -0.77$)$, the difference was not statistically significant $(P=0.32)$.

\section{$Q_{\max }$}

Six studies involving 502 participants, five studies involving 368 participants, six studies involving 368 participants and three studies involving 104 participants included data representing $Q_{\max }$ changes at postoperative 1 month (Figure 6A), 6 months (Figure 6B), 12 months (Figure 6C) and 24 months (Figure 6D), respectively.

Compared with baseline, $Q_{\max }$ had significant increases at postoperative 1 month (WMD 4.40, 95\% CI 3.00-5.80, $P<0.00001$ ), 6 months (WMD 4.71, 95\% CI 2.62-6.81, $P<0.0001$ ), 12 months (WMD 5.60, 95\% CI 4.19-7.02, $P<0.00001$ ) and 24 months (WMD 5.89, 95\% CI 5.08-6.7, $P<0.00001)$.

\section{PVR volume}

Six studies involving 476 participants, five studies involving 348 participants, six studies involving 369 participants and three studies involving 104 participants included data representing PVR volume changes at postoperative 1 month (Figure 7A), 6 months (Figure 7B), 12 months (Figure 7C) and 24 months (Figure 7D), respectively. 


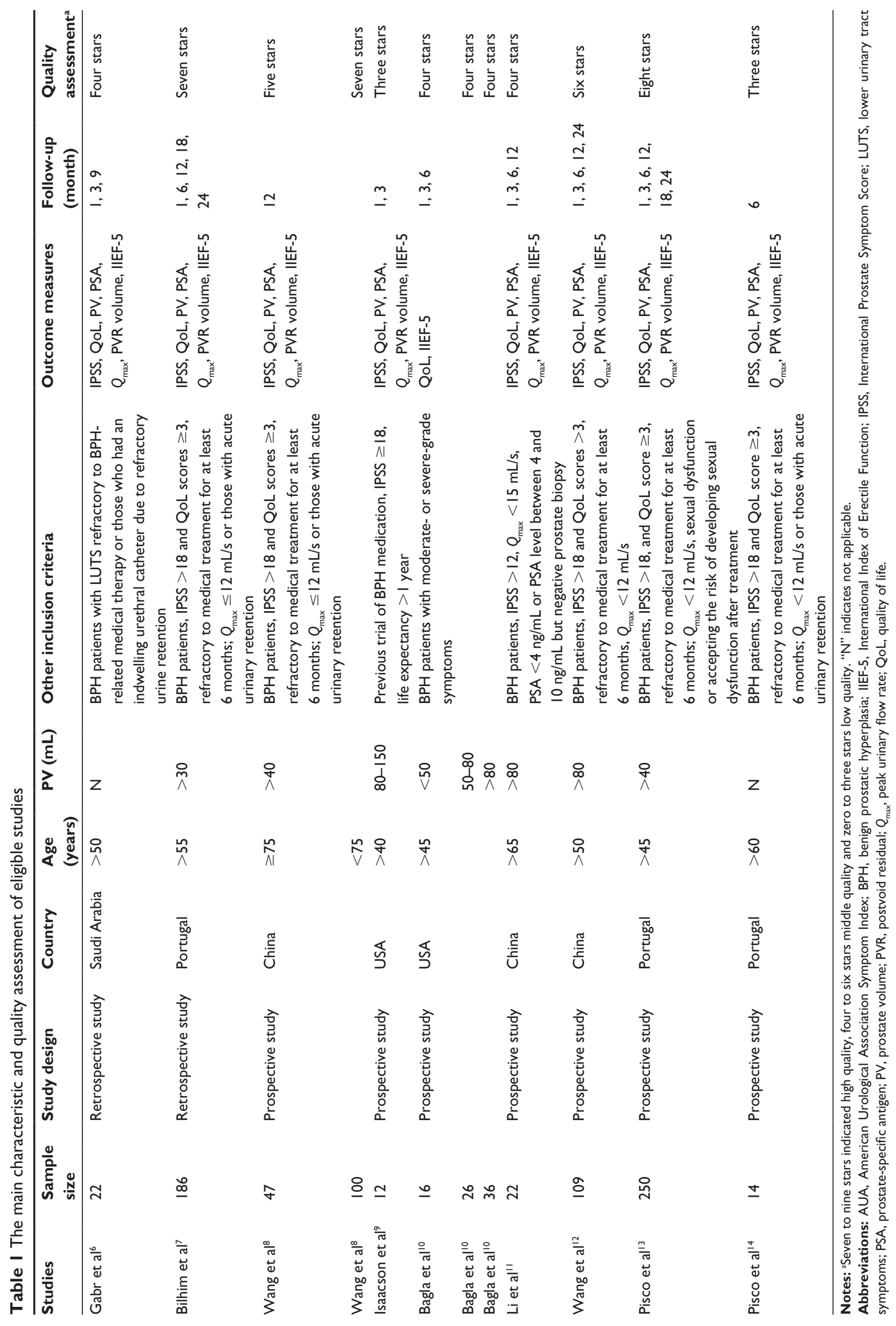




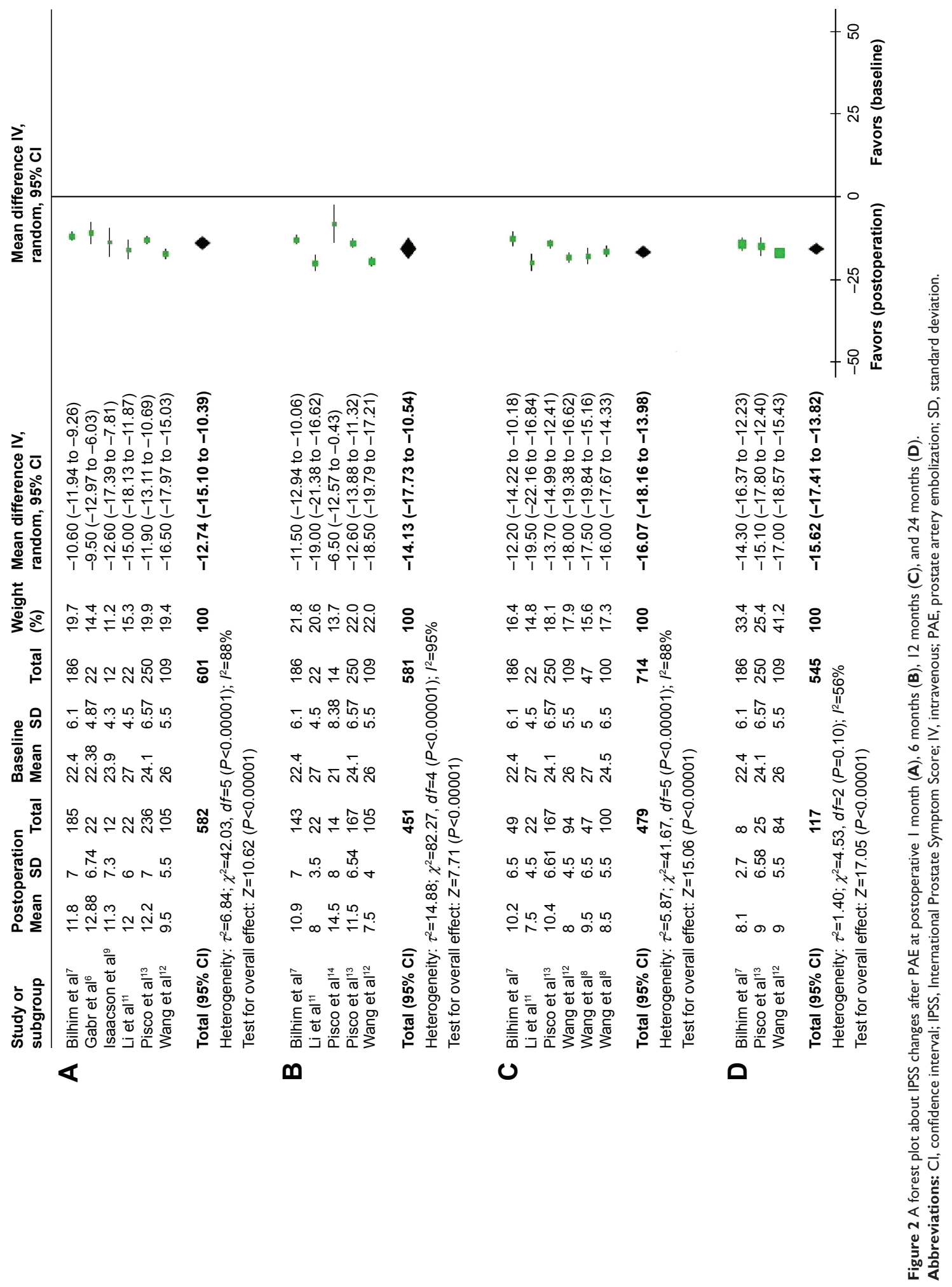




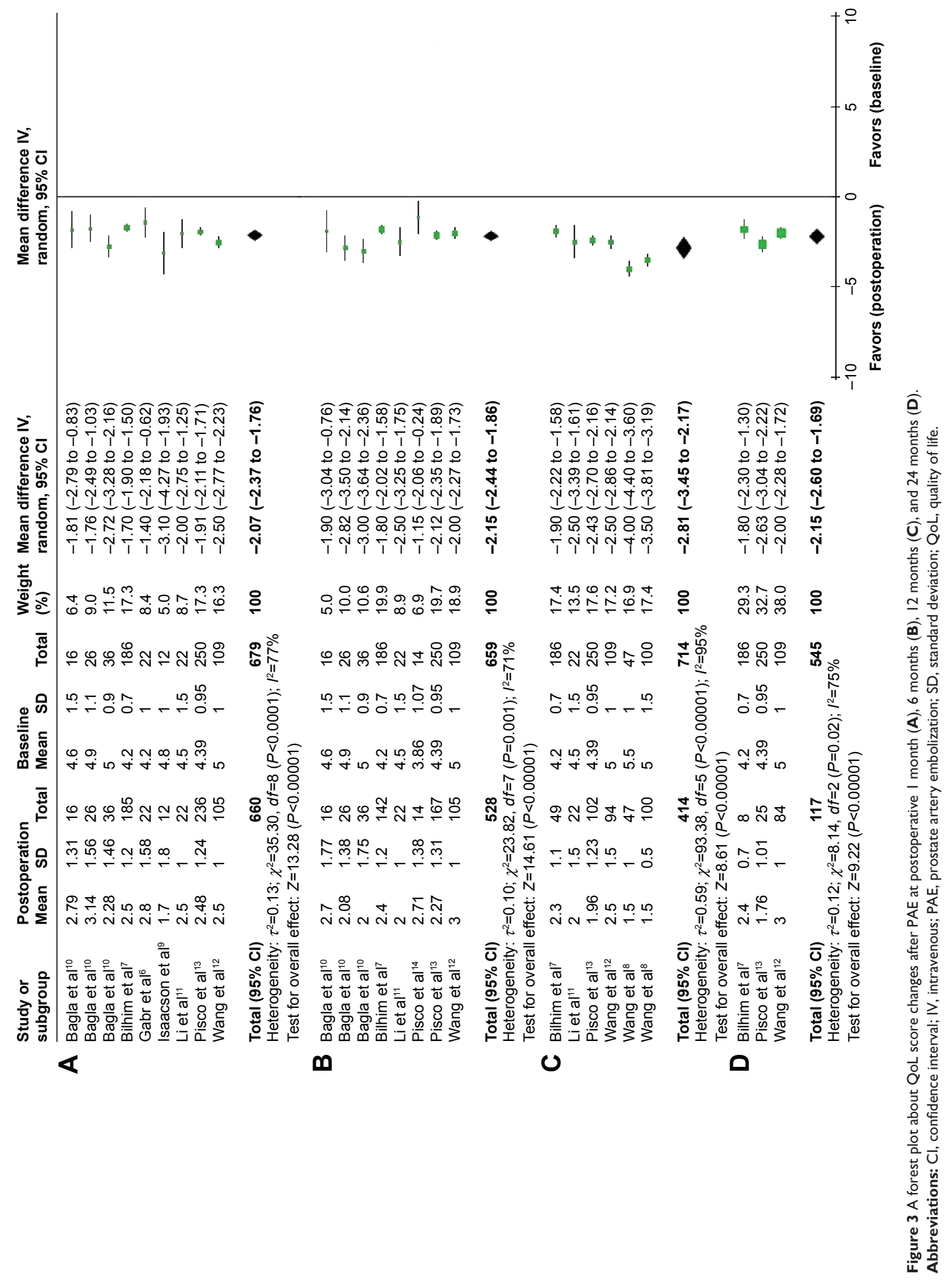




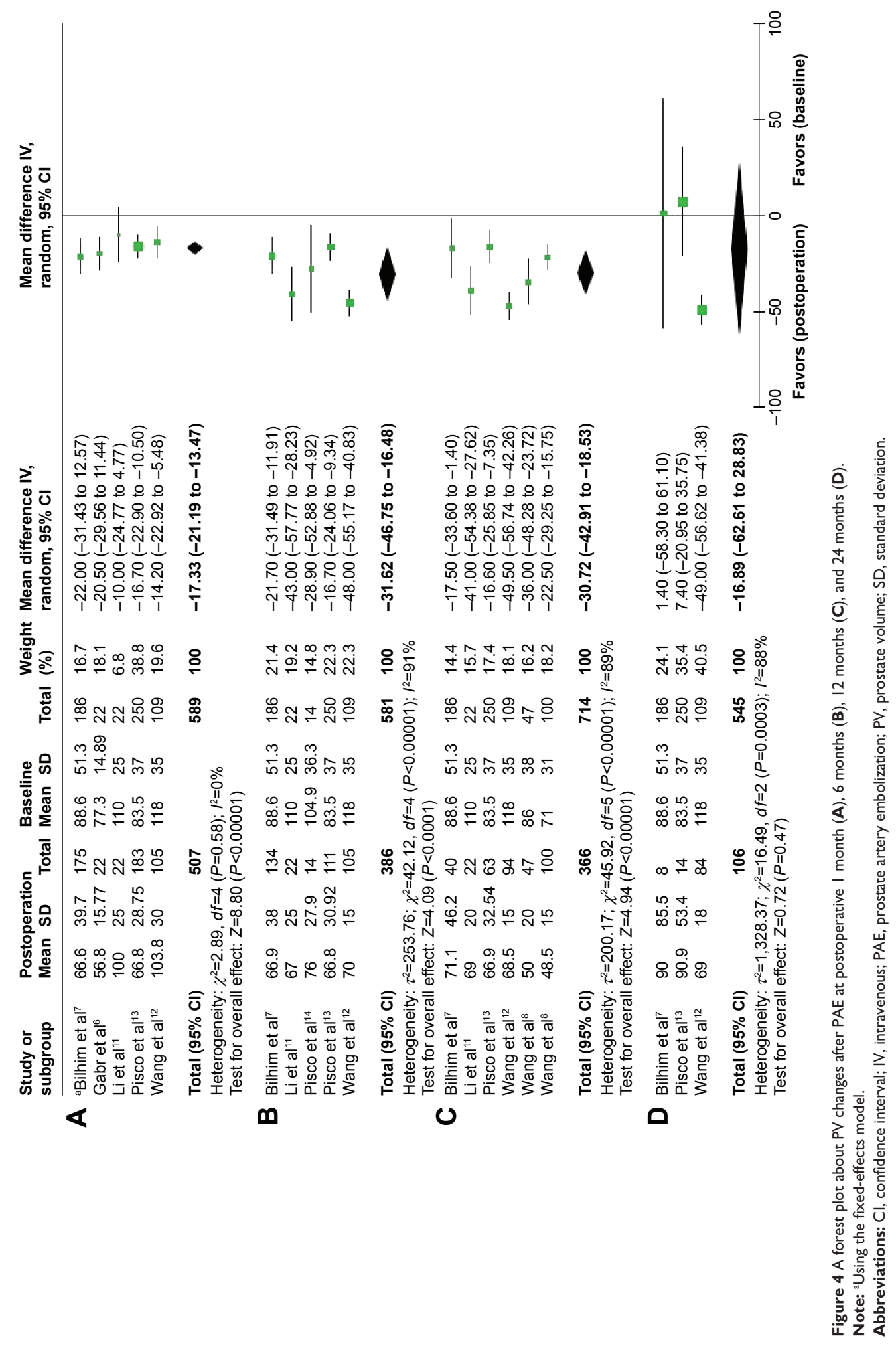




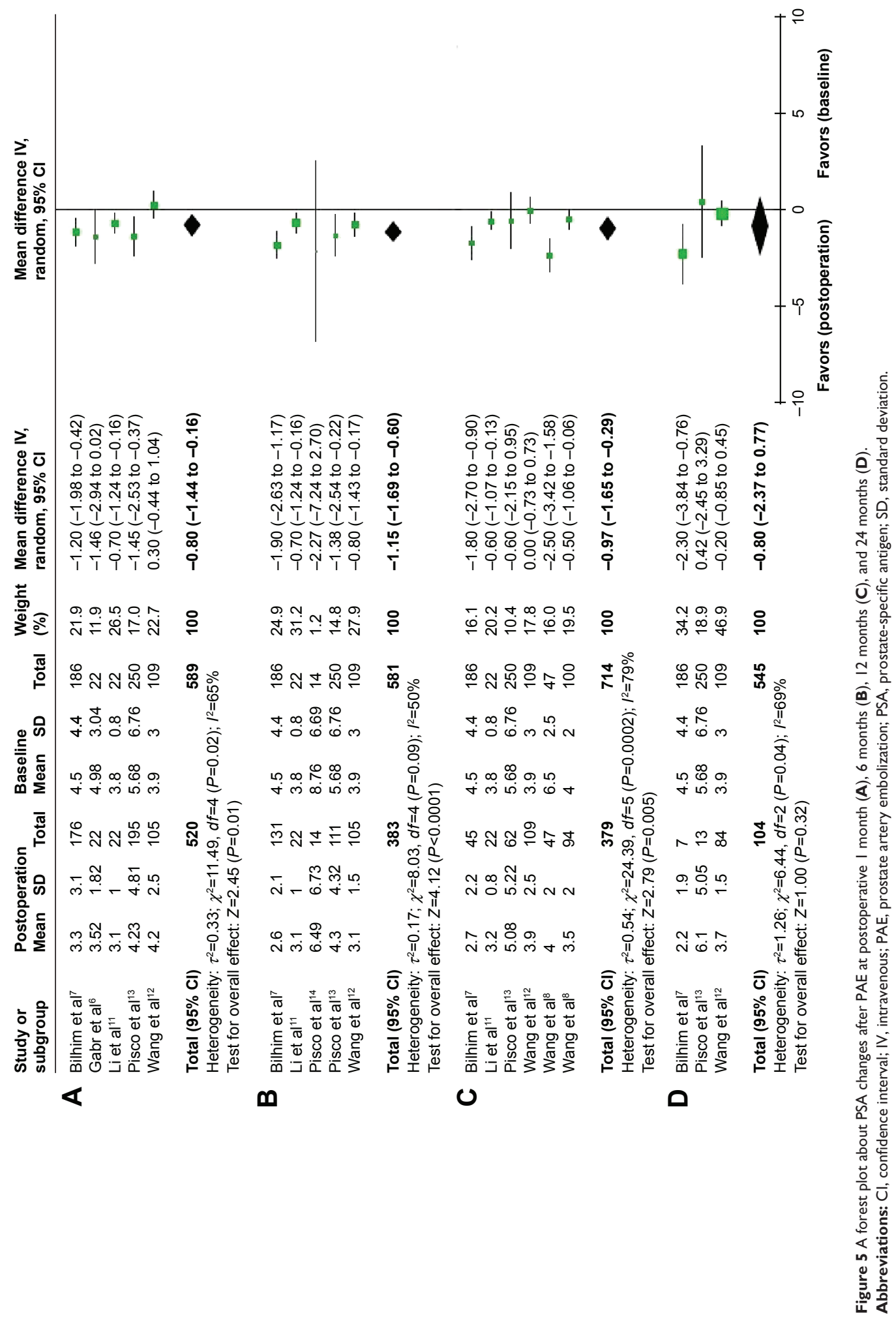




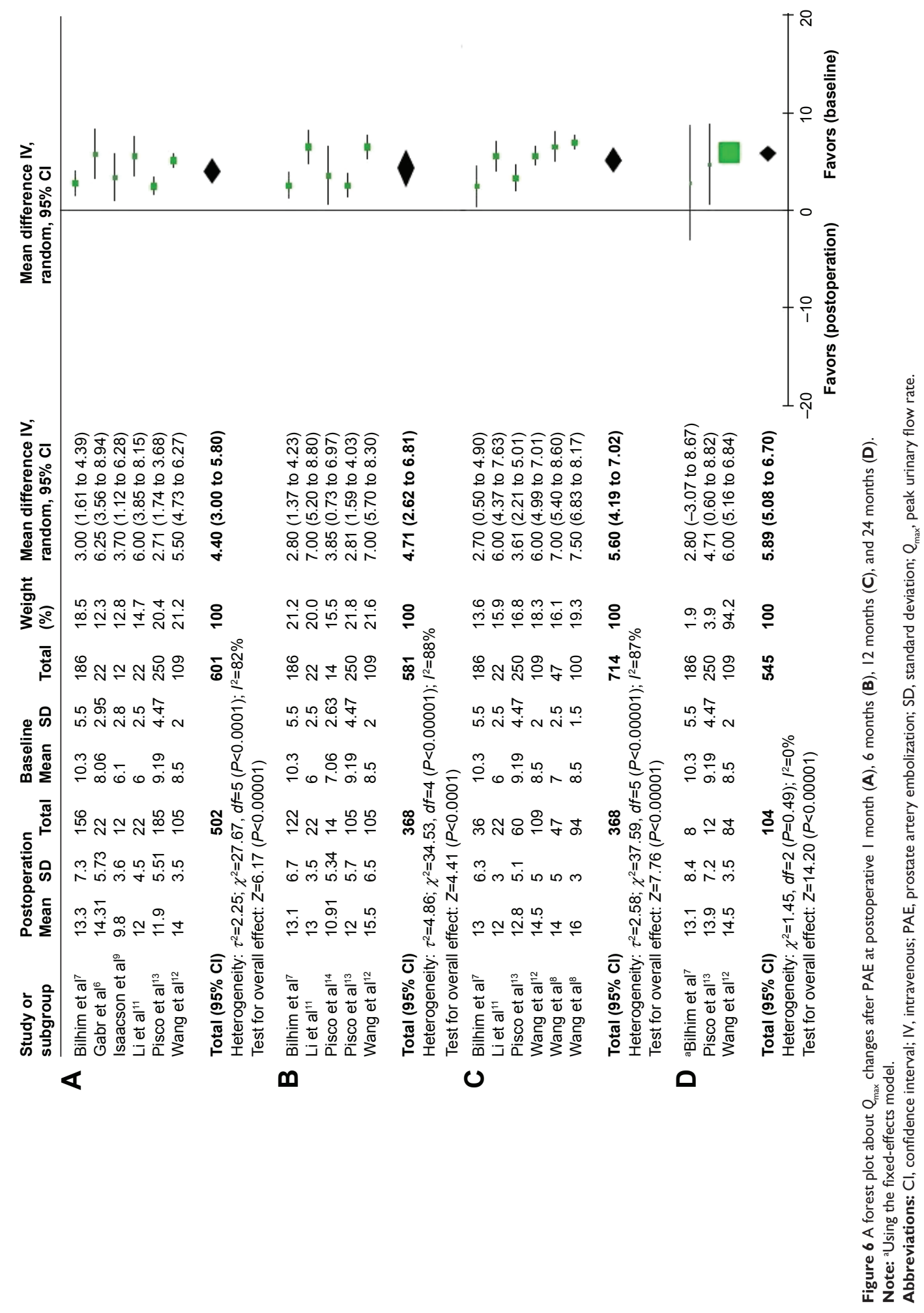




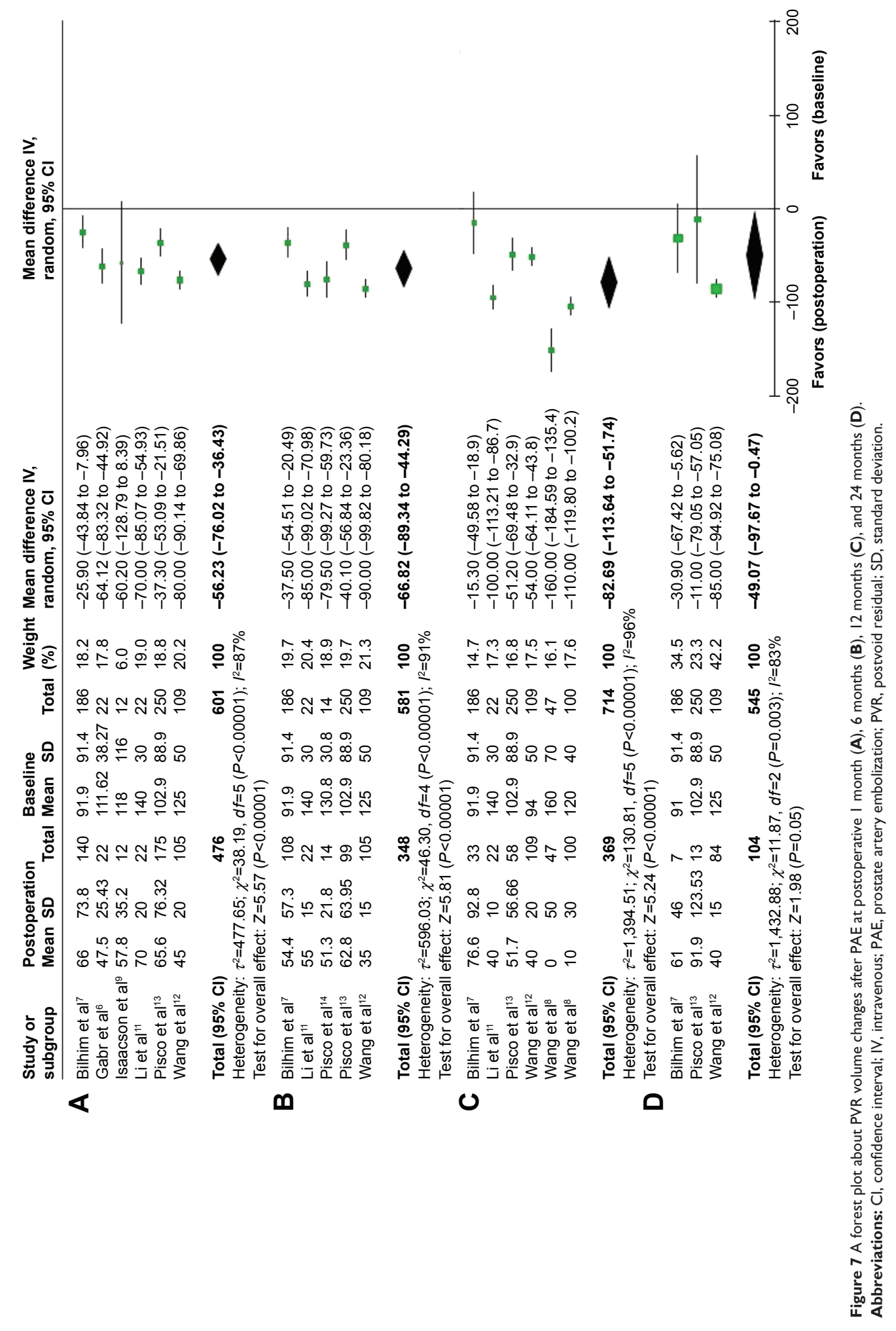


Compared with baseline, PVR volume had significant decreases at postoperative 1 month (WMD -56.23, 95\% CI -76.02 to $-36.34, P<0.00001$ ), 6 months (WMD -66.82 , 95\% CI -89.34 to $-44.29, P<0.00001), 12$ months (WMD $-82.69,95 \% \mathrm{CI}-113.64$ to $-51.74, P<0.00001$ ) and 24 months (WMD $-49.07,95 \%$ CI -97.67 to $-0.47, P=0.05$ ).

\section{IIEF-5 scores}

Nine studies involving 609 participants, eight studies involving 463 participants, six studies involving 372 participants and three studies involving 102 participants included data representing IIEF-5 score changes at postoperative 1 month (Figure 8A), 6 months (Figure 8B), 12 months (Figure 8C) and 24 months (Figure 8D), respectively.

Compared with baseline, the IIEF-5 scores were slightly increased at postoperative 1 month (WMD 0.49, 95\%
CI -0.30-1.28), but the difference was not statistically significant $(P=0.23)$. There were significant increases at postoperative 6 months (WMD 1.29, 95\% CI 0.48-2.10, $P=0.002$ ) and 12 months (WMD 1.36, 95\% CI 0.69-2.02, $P<0.0001)$. However, a slight decrease turned up at postoperative 24 months (WMD $-0.81,95 \%$ CI $-2.08-0.46$ ), which was not statistically significant $(P=0.21)$.

\section{Changes after PAE on large volume (PV $\geq 80 \mathrm{~mL}$ ) BPH}

Four studies, involving 179 participants, included data representing changes in the large volume $\mathrm{BPH}(\mathrm{PV}>80 \mathrm{~mL}){ }^{9-12}$ All the results matched the earlier findings, except that PSA had no obvious decrease during the 3-month follow-up and that the IIEF-5 scores had no significant changes during the 12-month follow-up. The comparison of changes after

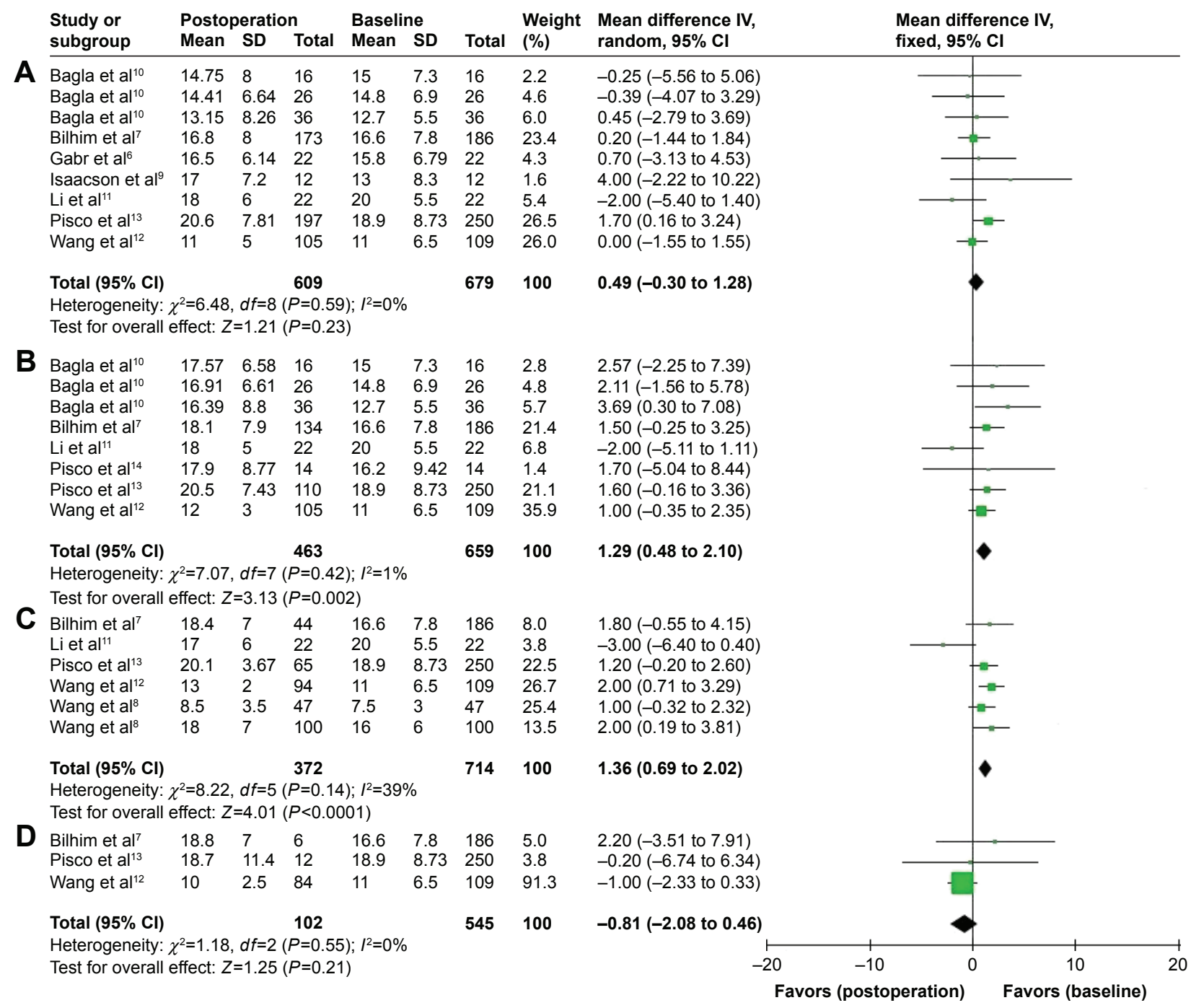

Figure 8 A forest plot about IIEF-5 score changes after PAE at postoperative I month (A), 6 months (B), 12 months (C), and 24 months (D). Abbreviations: Cl, confidence interval; IIEF-5, International Index of Erectile Function; IV, intravenous; PAE, prostate artery embolization; SD, standard deviation. 


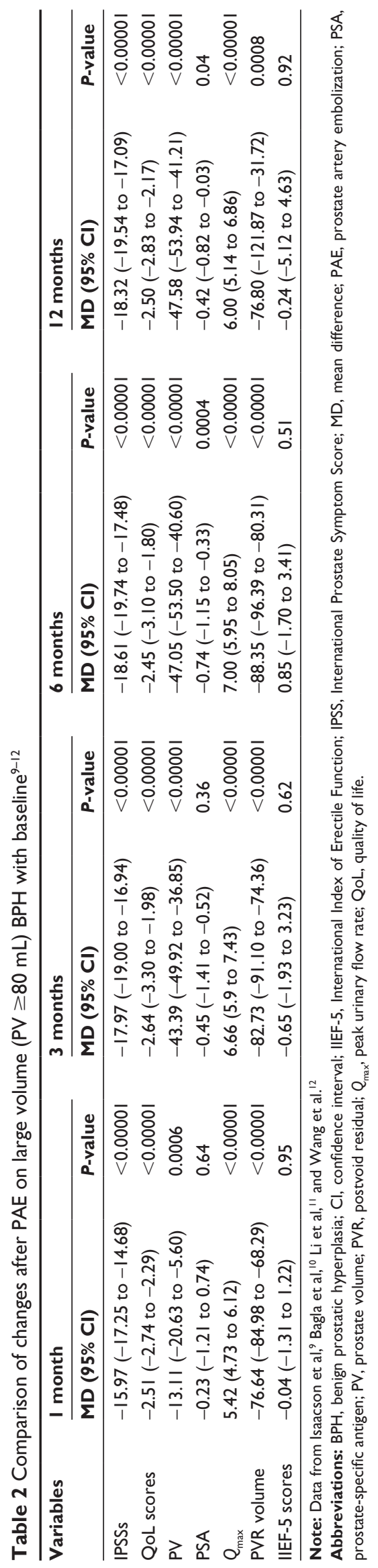

PAE on large volume ( $\mathrm{PV} \geq 80 \mathrm{~mL}$ ) BPH with baseline is presented in Table 2.

\section{Complications}

There were no life-threatening complications. Only one serious adverse event was seen in the study by Pisco et al: ${ }^{14}$ a case of a small area $\left(1.5 \mathrm{~cm}^{2}\right)$ of bladder wall ischemia in the right side of the base without involvement of the urethra or urethral orifices. The area of ischemia at the bladder base was removed by surgery without further complications.

Burning sensation in urethra $(87 / 840,10.4 \%)$ during the procedure seemed to be the main complication. Hematuria occurred in 57/840 (6.8\%) participants, hematospermia in $49 / 840$ (5.8\%), a small rectal bleeding in $38 / 840$ (4.5\%) and inguinal hematoma in 16/840 (1.9\%). All these complications disappeared spontaneously without any treatment. In all, 21/840 (2.9\%) participants developed urinary tract infection and all responded to suitable antibiotics. A total of 80/840 (9.5\%) participants had acute urinary retention (AUR) at 1-3 days after PAE. For relief, a temporary bladder catheter was placed, and they were able to void spontaneously before discharge. There were no cases of sexual impotence or retrograde ejaculation. Complications reported in the eligible studies are presented in Table 3.

\section{Discussion}

PAE was first utilized in the 1970 s to treat refractory bleeding following prostatic interventions as well as for intractable hematuria. ${ }^{15}$ It demonstrated a successful reduction in PV without serious complications in human beings in $2010 .^{2}$ The rationale for PAE is that prostate ischemia leads to PV reduction and hence clinical improvement. ${ }^{16}$

In this meta-analysis, compared with baseline, there were significant improvements in the IPSSs (-12.74 points), QoL scores (-2.07 points), PV $(-17.33 \mathrm{~mL})$, PSA $(-0.80 \mathrm{ng} / \mathrm{mL})$, $Q_{\text {max }}(+4.4 \mathrm{~mL} / \mathrm{s})$ and PVR volume $(-56.23 \mathrm{~mL})$ after PAE at postoperative 1 month. It implied that PAE could take effect quickly. Furthermore, the IPSSs ( -15.62 points), QoL scores $\left(-2.15\right.$ points), $Q_{\max }(+5.89 \mathrm{~mL} / \mathrm{s})$ and PVR volume $(-49.07 \mathrm{~mL})$ still had significant improvements during the 24-month follow-up, suggesting that PAE had good control of symptoms within 2 years.

For PV and PSA, significant decreases were found during the 12-month follow-up, but not at postoperative 24 months. We thought that the effect of PAE cannot be maintained in the long-term period. Besides prostate size increasing with 
Table 3 Complications reported in the eligible studies

\begin{tabular}{|c|c|c|c|c|c|c|c|c|}
\hline \multirow[t]{2}{*}{ Studies } & \multirow{2}{*}{$\begin{array}{l}\text { Sample } \\
\text { size }\end{array}$} & \multicolumn{7}{|c|}{ Complications } \\
\hline & & $\begin{array}{l}\text { Urethral } \\
\text { burning }\end{array}$ & $\begin{array}{l}\text { Urinary tract } \\
\text { infection }\end{array}$ & Hematuria & Hematospermia & $\begin{array}{l}\text { Rectal } \\
\text { bleeding }\end{array}$ & AUR & $\begin{array}{l}\text { Inguinal } \\
\text { hematoma }\end{array}$ \\
\hline Gabr et $\mathrm{al}^{6}$ & 22 & 15 & 0 & 0 & 0 & 0 & 0 & 0 \\
\hline Bilhim et $\mathrm{al}^{7}$ & 186 & 0 & I & 14 & 15 & 10 & 9 & 6 \\
\hline Wang et $\mathrm{al}^{8}$ & 47 & 10 & 0 & 6 & 4 & 4 & 16 & 3 \\
\hline Wang et $\mathrm{al}^{8}$ & 100 & 12 & 0 & 8 & 8 & 7 & 9 & 3 \\
\hline Isaacson et al ${ }^{9}$ & 12 & 0 & I & I & 1 & 0 & 1 & 0 \\
\hline Bagla et al ${ }^{10}$ & 78 & 0 & I & 0 & 0 & 0 & 0 & I \\
\hline Li et al" & 22 & 8 & 0 & 3 & 2 & 3 & 7 & 0 \\
\hline Wang et $\mathrm{al}^{12}$ & 109 & 19 & 0 & 11 & 9 & 8 & 31 & 3 \\
\hline Pisco et $\mathrm{al}^{13}$ & 250 & 23 & 19 & 14 & 10 & 6 & 6 & 0 \\
\hline Pisco et $\mathrm{al}^{14}$ & 14 & 0 & 2 & 0 & 0 & 0 & 1 & 0 \\
\hline Total & 840 & 87 & 24 & 57 & 49 & 38 & 80 & 16 \\
\hline
\end{tabular}

Abbreviation: AUR, acute urinary retention.

age, revascularization of the prostatic arteries after PAE may play a role in prostate regrowth. Pisco et a ${ }^{13}$ observed this kind of revascularization in their patients with second PAE. Interestingly, the IPSSs still had a significant decrease despite prostatic enlargement at postoperative 24 months. This may suggest that physical reduction of the obstructing tissue was not the only reason for the improvement in LUTS after PAE.

In terms of the IIEF-5 scores, there was no significant increase until 6 months after PAE. The epidemiological evidence had suggested a clear and clinically meaningful association between LUTS and sexual dysfunction that was independent of age and comorbidity. ${ }^{17}$ Along with the continuous improvement in LUTS, the IIEF-5 scores started to increase.

In addition, patients with large volume ( $\mathrm{PV} \geq 80 \mathrm{~mL}$ ) BPH are often elderly and may have severe comorbidities. They have increased operative risk of undergoing TURP/open surgery or refuse any surgical treatment. ${ }^{18}$ In this meta-analysis, for large volume ( $\mathrm{PV} \geq 80 \mathrm{~mL}$ ) BPH, there were significant improvements in the IPSSs $(-18.32$ points), QoL scores ( -2.50 points), PV $(-47.58 \mathrm{~mL})$, $Q_{\text {max }}(+6.00 \mathrm{~mL} / \mathrm{s})$ and PVR volume $(-76.80 \mathrm{~mL})$ after PAE during the 12-month follow-up, and there were no lifethreatening complications. PAE does offer the ability to treat $\mathrm{BPH}$ in these patients, due to its minimally invasive nature with low morbidity and the possibility to use local anesthetic without sedation. ${ }^{8}$

Subsequent studies have further compared the clinical outcome of PAE versus TURP. Carnevale et al ${ }^{19}$ reported that both groups experienced significant improvement in IPSS, QoL, PV, and $Q_{\max }$ during the 12-month follow-up. TURP resulted in significantly higher $Q_{\max }$ and smaller PV than PAE but required spinal anesthesia and hospitalization, while IIEF scores were significantly higher in the PAE group. Gao et $\mathrm{al}^{20}$ reported a similar result during the 24-month follow-up, except that the PAE group showed more complications, mostly related to AUR (25.9\%), postembolization syndrome $(11.1 \%)$ and treatment failures $(5.3 \%$ technical; $9.4 \%$ clinical).

Nevertheless, there are some limitations to our analysis. The major limitations include heterogeneity in the participants chosen, different materials and sizes of embolic agents and bilateral or unilateral embolization. The subgroup and sensitivity analysis or a random-effects model might reduce these limitations, but cannot eliminate. Additionally, the sample sizes of some included studies were small, and there was no long-term follow-up study. Data in the studies covered by this meta-analysis are insufficient to determine whether or not PAE is as good as TURP. Stratified trials with high volume and long follow-up time are awaited to strengthen the evidence and to update our findings.

PAE is an effective, safe and well-tolerable treatment for LUTS related to $\mathrm{BPH}$, including large volume (PV $\geq 80 \mathrm{~mL}$ ) $\mathrm{BPH}$, with good short-term follow-up. Studies with large number of cases and longer follow-up time are needed to validate our results.

\section{Disclosure}

The authors report no conflicts of interest in this work.

\section{References}

1. McVary KT, Roehrborn CG, Avins AL, et al. Update on AUA guideline on the management of benign prostatic hyperplasia. J Urol. 2011; 185(5):1793-1803. 
2. Carnevale FC, Antunes AA, da Motta Leal Filho JM, et al. Prostatic artery embolization as a primary treatment for benign prostatic hyperplasia: preliminary results in two patients. Cardiovasc Intervent Radiol. 2010;33(2):355-361.

3. Stucki P, Marini L, Mattei A, Xafis K, Boldini M, Danuser H. Bipolar versus monopolar transurethral resection of the prostate: a prospective randomized trial focusing on bleeding complications. J Urol. 2015; 193(4):1371-1375.

4. Jones P, Rai BP, Nair R, Somani BK. Current status of prostate artery embolization for lower urinary tract symptoms: review of world literature. Urology. 2015;86(4):676-681.

5. McWilliams JP, Kuo MD, Rose SC, et al. Society of interventional radiology position statement: prostate artery embolization for treatment of benign disease of the prostate. J Vasc Interv Radiol. 2014;25(9): 1349-1351.

6. Gabr AH, Gabr MF, Elmohamady BN, Ahmed AF. Prostatic artery embolization: a promising technique in the treatment of high-risk patients with benign prostatic hyperplasia. Urol Int. 2016. Epub 2016 Jun 21.

7. Bilhim T, Pisco J, Pereira JA, et al. Predictors of clinical outcome after prostate artery embolization with spherical and nonspherical polyvinyl alcohol particles in patients with benign prostatic hyperplasia. Radiology. 2016;281(1):289-300.

8. Wang MQ, Wang Y, Yan JY, et al. Prostatic artery embolization for the treatment of symptomatic benign prostatic hyperplasia in men $\geq 75$ years: a prospective single-center study. World J Urol. 2016; 34(9):1275-1283.

9. Isaacson AJ, Raynor MC, Yu H, Burke CT. Prostatic artery embolization using embosphere microspheres for prostates measuring $80-150 \mathrm{~cm}(3)$ : early results from a US trial. J Vasc Interv Radiol. 2016;27(5):709-714.

10. Bagla S, Smirniotopoulos JB, Orlando JC, van Breda A, Vadlamudi V. Comparative analysis of prostate volume as a predictor of outcome in prostate artery embolization. J Vasc Interv Radiol. 2015;26(12):1832-1838.

11. Li Q, Duan F, Wang MQ, Zhang GD, Yuan K. Prostatic arterial embolization with small sized particles for the treatment of lower urinary tract symptoms due to large benign prostatic hyperplasia: preliminary results. Chin Med J (Engl). 2015;128(15):2072-2077.
12. Wang MQ, Guo LP, Zhang GD, et al. Prostatic arterial embolization for the treatment of lower urinary tract symptoms due to large $(>80 \mathrm{~mL})$ benign prostatic hyperplasia: results of midterm follow-up from Chinese population. BMC Urol. 2015;15:33.

13. Pisco JM, Rio Tinto H, Campos Pinheiro L, et al. Embolisation of prostatic arteries as treatment of moderate to severe lower urinary symptoms (LUTS) secondary to benign hyperplasia: results of short- and mid-term follow-up. Eur Radiol. 2013;23(9):2561-2572.

14. Pisco JM, Pinheiro LC, Bilhim T, Duarte M, Mendes JR, Oliveira AG. Prostatic arterial embolization to treat benign prostatic hyperplasia. J Vasc Interv Radiol. 2011;22(1):11-19.

15. Aoun F, Marcelis Q, Roumeguere T. Minimally invasive devices for treating lower urinary tract symptoms in benign prostate hyperplasia: technology update. Res Rep Urol. 2015;7:125-136.

16. Sun F, Sánchez FM, Crisóstomo V, et al. Transarterial prostatic embolization: initial experience in a canine model. AJR Am J Roentgenol. 2011; 197(2):495-501.

17. Gacci M, Eardley I, Giuliano F, et al. Critical analysis of the relationship between sexual dysfunctions and lower urinary tract symptoms due to benign prostatic hyperplasia. Eur Urol. 2011;60(4):809-825.

18. Choi SY, Kim TH, Myung SC, et al. Impact of changing trends in medical therapy on surgery for benign prostatic hyperplasia over two decades. Korean J Urol. 2012;53(1):23-28.

19. Carnevale FC, Iscaife A, Yoshinaga EM, Moreira AM, Antunes AA, Srougi M. Transurethral resection of the prostate (TURP) versus original and perfected prostate artery embolization (PAE) due to benign prostatic hyperplasia (BPH): preliminary results of a single center, prospective, urodynamic-controlled analysis. Cardiovasc Intervent Radiol. 2016;39(1):44-52.

20. Gao YA, Huang Y, Zhang R, et al. Benign prostatic hyperplasia: prostatic arterial embolization versus transurethral resection of the prostate - a prospective, randomized, and controlled clinical trial. Radiology. 2014;270(3):920-928.
Clinical Interventions in Aging

\section{Publish your work in this journal}

Clinical Interventions in Aging is an international, peer-reviewed journal focusing on evidence-based reports on the value or lack thereof of treatments intended to prevent or delay the onset of maladaptive correlates of aging in human beings. This journal is indexed on PubMed Central, MedLine,

\section{Dovepress}

CAS, Scopus and the Elsevier Bibliographic databases. The manuscript management system is completely online and includes a very quick and fair peer-review system, which is all easy to use. Visit http://www.dovepress. com/testimonials.php to read real quotes from published authors. 